\title{
Educação ambiental aliada ao método de recuperação por plantio em uma nascente localizada na área urbana do municipio de Itapira - SP
}

Environmental education allied to recovery method for spring planting in a located in urban area of the city of Itapira - SP

\author{
Anderson Martelli \\ Biólogo da Secretaria de Agricultura e Meio Ambiente de Itapira - SP \\ Docênte da Faculdade FMG - Mogi Guaçu - SP
}

\section{Resumo}

Atualmente, a preocupação com o ambiente está presente na vida de grande parte da população. Estudos sobre o estado de conservação de nascentes e a estrutura de suas matas ciliares se mostram de extrema importância para embasar programas de recomposição desses ecossistemas. Neste artigo discute-se a importância da recomposição vegetal por plantio direto em uma área de preservação permanente localizada ao redor de duas nascentes encontradas no perímetro urbano do município de Itapira - SP através de ações de educação ambiental desenvolvidas pela Secretaria de Agricultura e Meio Ambiente junto aos integrantes do Consorcio Intermunicipal de Saneamento Básico do Circuito das Águas e moradores do entorno. Essas faixas de vegetação exercem a função de barreira e proteção dos cursos d'água, servindo como corredores ecológicos, unindo fragmentos de matas, permitindo o trânsito de animais e retirando-os do isolamento e a fixação do carbono atmosférico, contribuindo assim para a redução do efeito-estufa. O estudo procura ainda, subsidiar as autoridades e a sociedade para a conscientização e preservação do meio natural, uma vez que há carência de informações e a preocupação com a possível ameaça de escassez hídrica que tanto se alardeia pelo mundo todo.

Palavras-chave: Nascente, Matas Ciliares, Educação Ambiental, Itapira.

\begin{abstract}
Currently, concern for the environment is present in the lives of most of the population. Studies on the state of conservation of water sources and the structure of its riparian show is extremely important to support programs of restoration of these ecosystems. This article discusses the importance of restoring vegetation by tillage in a permanent preservation area located around two springs found in the urban perimeter of Itapira - SP through environmental education programs developed by the Department of Agriculture and Environment with the members of the Intermunicipal Consortium of Sanitation Water Circuit and surrounding residents. These vegetation belts exert barrier function and protection of watercourses, serving as ecological corridors, linking forest fragments, allowing the transit of animals and removing them from isolation and fixation of atmospheric carbon, thereby contributing to the reduction of greenhouse effect. The study seeks to further subsidize the authorities and society to raise awareness and preservation of the natural environment, since there is a lack of information and concern about the possible threat of water scarcity that is both trumpets around the world.
\end{abstract}

Keywords: Spring, Riparian Forest, Environmental Education, Itapira. 


\section{INTRODUÇÃO}

Nas últimas décadas o Brasil passou por um processo de desenvolvimento sem um planejamento adequado, que resultou em alguns casos, em prejuízo para a gestão sustentável das futuras gerações, pois ocorreu e está ocorrendo uma destruição dos recursos naturais, levando em consideração a destruição dos mananciais de água potável e principalmente das nascentes.

O uso insustentável dos recursos naturais tornou-se o alvo de estudo de pesquisadores nesses últimos anos. A poluição da água e da atmosfera, o desflorestamento, o uso incorreto da terra, a degradação dos recursos hídricos entre outros, caracterizam os problemas ambientais mais agravantes no mundo contemporâneo e estimulam a sensibilização da sociedade para que sejam tomadas providências imediatas, dando primazia à conservação dos recursos essenciais à qualidade de vida do planeta (OLIVA Jr. \& SOUSA, 2012).

Tratando-se de recursos naturais, Calheiro (2007) define nascente como um afloramento do lençol freático, que vai dar origem a uma fonte de água de acúmulo (represa), ou cursos d'água (ribeirões ou rios). De acordo com o dicionário Geológico-Geomorfológico, nascente é o mesmo que cabeceira de um rio, acrescentado ainda que, não é um ponto e sim uma zona (área) considerável da superfície terrestre (GUERRA, 2003). Portanto, uma vez a nascente sendo o mesmo que cabeceira, segundo este mesmo autor, o conceito de cabeceira é o seguinte: "área onde existem os olhos d’água que dão origem a um curso fluvial".

Já as matas ciliares, são formações florestais que ocorrem ao longo de cursos d'água e no entorno de nascentes, fundamentais na manutenção da quantidade e qualidade da água de um reservatório, sendo responsáveis pelo aumento da infiltração de água no solo, redução do processo erosivo, contenção de barrancos, dentre outras vantagens (CARVALHO, 2000; BOTELHO; DAVIDE, 2002).

No entanto, apesar desse ecossistema desempenhar importantes funções, contribuindo com a qualidade dos recursos hídricos, o mesmo tem sofrido constantes agressões, seja pela expansão agrícola, pelo crescimento demográfico desordenado, ou ainda pela criação de usinas hidrelétricas, reduzindo sobremaneira sua extensão vegetacional. Nesse contexto, torna-se necessária a adoção de ações que visem a promoção da recomposição da vegetação destes ambientes, e com isso garantir a manutenção da qualidade dos recursos hídricos de uma bacia hidrográfica (FERREIRA et al., 2009).

Ao longo dos anos, as áreas de preservação permanente (APP's) às margens dos cursos d'água vêm sofrendo degradações, principalmente nas áreas urbanas, com a retirada parcial ou total da vegetação nessa faixa, a qual deveria ser mantida intacta por garantir a preservação dos recursos hídricos, a estabilidade geológica e a biodiversidade (TERRES; MULLER, 2008; ANDRADE et al., 2005; DURIGAN; SILVEIRA, 1999).

Dentre as leis brasileiras que visam à conservação dos recursos naturais, destaca-se o Código Florestal Brasileiro, o qual conceitua e regimenta as APPs (OKUYAMA et al. 2012).

A Resolução CONAMA n ${ }^{\circ} .303$ de 20 de março de 2002, que dispõe sobre parâmetros, definições e limites de APP, define as nascentes como sendo "local onde aflora naturalmente, mesmo que de forma intermitente, a água subterrânea" e indica em seu Art. $3^{\circ}$, a área a ser preservada: "Art. $3^{\circ}$ Constitui Área de Preservação Permanente a área situada: ... II - ao redor de nascente ou olho d’água, ainda que intermitente, com raio mínimo de cinquenta metros de tal forma que proteja, em cada caso, a bacia hidrográfica contribuinte;"

Já a Lei Federal no . 12.561/12 revela em seu artigo $4^{\circ}$ a seguinte afirmação: "Considera-se Área de Preservação Permanente, em zonas rurais ou urbanas, para os efeitos desta Lei": IV - as áreas no entorno das nascentes e dos olhos d'água perenes, qualquer que seja sua situação topográfica, no raio mínimo de 50 (cinquenta) metros (BRASIL, 2012).

Assim, as áreas de nascentes são protegidas por lei desde 1965 (lei 4.771/65), quando foi instituído o Código Florestal Brasileiro, cobertas ou não por vegetação nativa com a função ambiental de preservar os recursos hídricos, a paisagem, estabilidade geológica, biodiversidade, o fluxo gênico de fauna e flora, proteger o solo e assegurar o bem-estar das populações humanas.

Sabe-se que o desenvolvimento urbano provoca o aumento da demanda por água, e ao mesmo tempo, a degradação dos mananciais em decorrência da sua contaminação pelos resíduos urbanos. As principais causas da contaminação se originam no despejo de poluentes oriundos dos esgotos domésticos e industriais, além de outras substâncias oriundas das culturas agrícolas em áreas próximas aos mananciais, sendo importante ressaltar que as substâncias agrotóxicas não agridem apenas a água superficial, mas os lençóis freáticos e o solo, causando inúmeros danos a esses recursos naturais, tornando-os inférteis e de baixa qualidade. Vale ressaltar que em nosso país a agricultura irrigada é a atividade que mais consome água, anualmente é responsável por $69 \%$ 
do consumo (OLIVA Jr.; SOUSA, 2012).

Portanto, faz-se necessária a recuperação e a proteção de áreas de nascentes buscando meios que possam revitalizá-las para manter o equilíbrio da biodiversidade presente nas áreas de veredas, contribuindo para manter o principal líquido da vida, a água.

A educação ambiental, como processo de educação política, busca formar para que a cidadania seja exercida e para uma ação transformadora, a fim de melhorar a qualidade de vida da coletividade. Não reforçando uma visão antropocêntrica que tem gerado tanta degradação e que coloca o ser humano como centro do universo e acima de todos os outros seres vivos, mas tendo claro que o equilíbrio de todos os ecossistemas, e, portanto do planeta, depende de relações equilibradas entre todos os seres vivos e não vivos da terra (PELICIONI, 2004).

A vegetação remanescente ao redor de uma nascente situada na área urbana do município de Itapira - SP descrita neste trabalho, nos dias atuais encontra-se comprometida devido ao mau uso da população, sendo observado um déficit moderado da sua vegetação nativa, o que acarreta uma diminuição da proteção do solo, tornando-a uma área mais propícia a erosão - processo de desgaste do solo, desagregação, arranque, transporte e deposição de sedimentos no curso de suas aguas, causando o assoreamento desta nascente, diminuindo a qualidade da água, afetando os ecossistemas que habitam o rio e desequilíbrio das relações ecológicas da região.

Segundo Botelho (2003), o método de recuperação por plantio de mudas é o mais usado no Brasil e apresenta como principais vantagens a garantia da densidade do plantio pela alta sobrevivência e ainda, espaçamento regular sendo necessário avaliar os fragmentos de mata nas proximidades da área a ser recuperada a fim de conhecer a vegetação local, para auxiliar na escolha das mudas e ter conhecimento das condições do solo e do clima da região.

Para Pelicioni (2004), transformar uma realidade é preciso conhecê-la profundamente, conhecer as necessidades, interesses, dificuldades, sonhos e expectativas dos grupos sociais que formam a sociedade. Definem-se a partir daí os instrumentos e a metodologia a ser utilizada em função dos objetivos estabelecidos. A ação educativa deve ser planejada junto com a população investigada e deve prever uma avaliação constante. A educação ambiental é fundamental na obtenção dos objetivos e metas estabelecidos para uma adequada gestão ambiental, em qualquer locali- dade. A eficiência da gestão de uma área urbana ou rural e determinada pelo grau de educação da população local.

Levando em consideração a importância da mata ciliar para o bem estar da população e por ser um tema pouco divulgado e considerando a urgência de recuperar as nascentes que exercem um papel fundamental na formação e manutenção dos recursos hídricos, esse trabalho apresenta como objetivo mostrar a importância da interação entre reconstituição ciliar de uma APP com o plantio direto de mudas de arvores nativas da região, visando a preservação e a estabilidade geológica, a biodiversidade, o fluxo gênico de fauna e flora, proteção do solo, ampliar a beleza cênica de uma paisagem, assegurar o bem-estar da população que vivem próximas ao local, aliada à Educação Ambiental junto a comunidade numa área urbana, ao redor de um fragmento de mata atlântica onde temos a ocorrência de duas nascentes que dão origem a um córrego sem denominação, afluente do Ribeirão da Penha, principal curso d'agua do município de Itapira - SP, de onde é realizado a captação de agua do município.

\section{MATERIAIS E MÉTODOS}

Caracterização do Município de Itapira

O Município de Itapira integra a Região Administrativa de Campinas e está localizado na região Sudeste, porção centro-leste do Estado de São Paulo, a 22 26'10" de latitude S e 4649'18"de longitude $\mathrm{W}$, distando aproximadamente $63 \mathrm{~km}$ (via anel de contorno) da cidade de Campinas e $159 \mathrm{~km}$ da capital do Estado.

Possui uma área de $518,385 \mathrm{~km}^{2}$, com uma estimativa populacional de 68.537 habitantes. $\mathrm{O}$ perímetro urbano apresenta uma área de 58.042 $\mathrm{m}^{2}$ com uma densidade demográfica de 132,21 habitantes por $\mathrm{km}^{2}$ (IBGE, 2010).

Acha-se incluído na "Serrania de Lindóia", segundo subdivisão geomorfológica do Estado de São Paulo proposta no Mapa Geomorfológico do Estado de São Paulo (IPT, 2006). Limita-se a oeste, com a "Zona do Mogi Guaçu", uma das três subdivisões propostas para as Depressões Periféricas Paulista, representadas pelas rochas da Bacia do Paraná.

O clima predominante na região é o Temperado Quente Úmido, de acordo com classificação de Köppen, havendo estações com mais de 60 dias secos, com temperatura máxima anual em cerca de $29^{\circ} \mathrm{C}$ e temperatura mínima anual em cerca de $5^{\circ} \mathrm{C}$, com médias anuais de precipitação em torno 


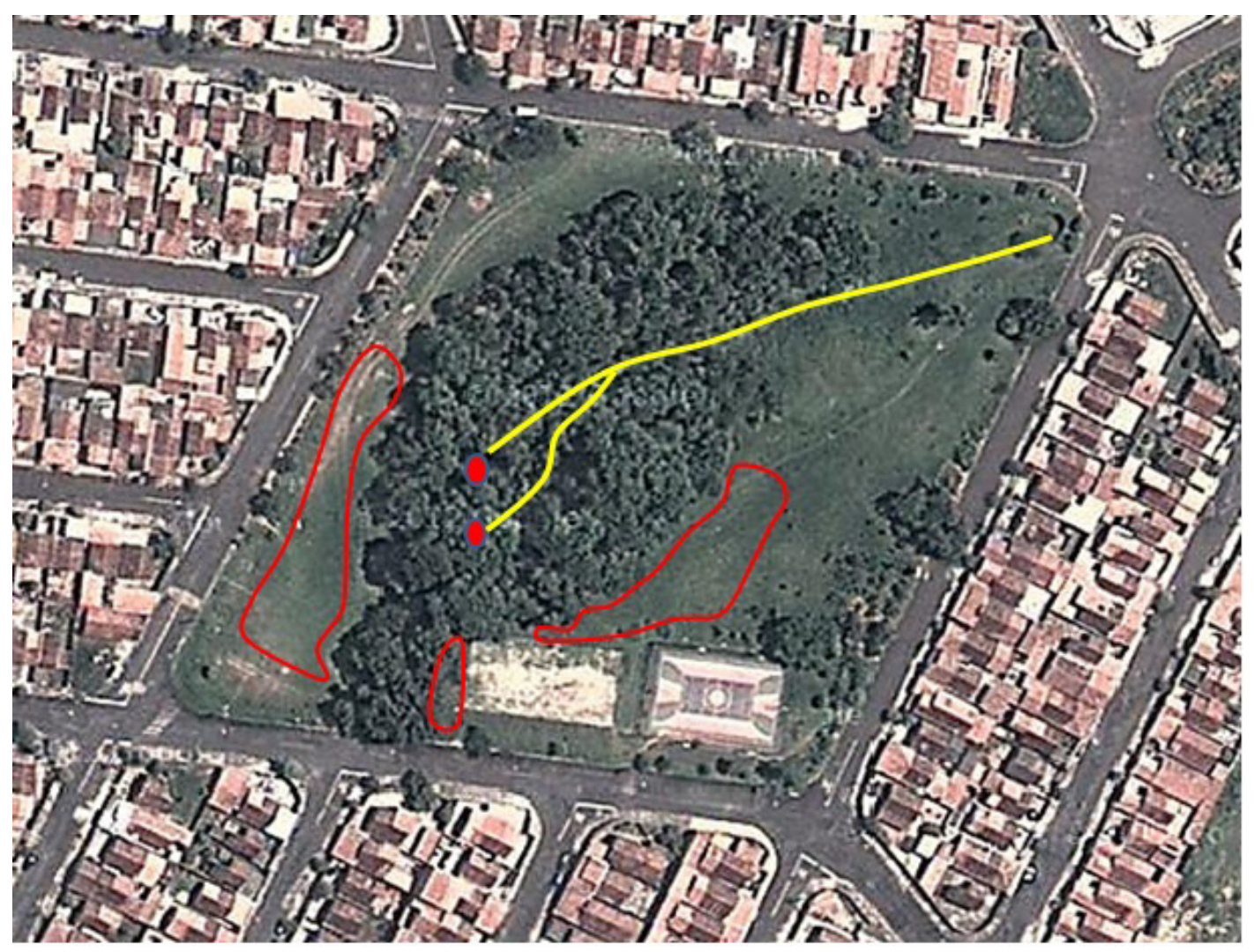

Figura 1. Vista geral da área onde foi realizada a ação. No contorno em vermelho, local do plantio direto das mudas; circulo em vermelho - localização das nascentes; em amarelo - curso d'agua sem denominação, afluente do Ribeirão da Penha. Imagem gerada a partir do google maps e modificada.

de $1.600 \mathrm{~mm}$ (SETZER, 1976).

A área de escolha do plantio situa-se no perímetro urbano do município de Itapira no bairro denominado Conjunto Habitacional Braz Cavenaghi, onde encontra-se uma área verde com a presença de duas nascentes figura 1 .

Essas águas dessas nascente sofrem uma confluência ainda no interior do fragmento florestal e vão dar origem a um córrego sem denominação, afluente do Ribeirão da Penha, principal curso d'agua do município o qual corta todo o perímetro urbano conforme demonstrado na figura 2 onde é possível observar o perímetro urbano demarcado em cinza e o Ribeirão da Penha cortando essa área.

Segundo estudo de Silveira e Bueno (2008), a área delimitada pela microbacia do Ribeirão da Penha em Itapira, é marcada por diversas ações antrópicas, como a retificação do Ribeirão da Penha, a construção de barragens, além da presença constante de ocupação em grande parte das vezes não planejada ou planejada, mas sem vistas aos aspectos ambientais.

Para a reconstituição ciliar, técnicos da Secretaria de Agricultura e Meio Ambiente de Itapira (SAMA) entraram em contato com o Consórcio Intermunicipal de Saneamento Básico do
Circuito das Aguas - CISBRA, onde Itapira e mais 11 municípios são integrantes para a participação conjunta dessa ação de educação ambiental e reconstituição da mata ciliar da cabeceira dessas nascentes.

\section{I Técnica de preparo da área do plantio}

O preparo do terreno para plantio compreendeu com uma roçada mecanizada da vegetação existente (predominantemente gramíneas). Posteriormente técnicos da SAMA e funcionários do viveiro municipal de mudas deslocaram até o local, sendo realizado a marcação das covas com posterior coroamento manual, com cerca de 60 $\mathrm{cm}$ de diâmetro para cada cova. Em seguida um trator do tipo Valmet 108 acoplado com um perfurador de solo realizou a abertura das covas com dimensões de aproximadamente 30 centímetros de diâmetro por 40 centímetros de profundidade.

O solo referente aos coveamentos foi misturado com $20 \%$ do volume da cova com adubo orgânico (esterco de curral) e o retorno deste solo a seu respectivo buraco.

Uma semana antes do plantio foi realizada a separação das mudas no Viveiro Municipal vinculado a SAMA. No dia do plantio, as mudas 


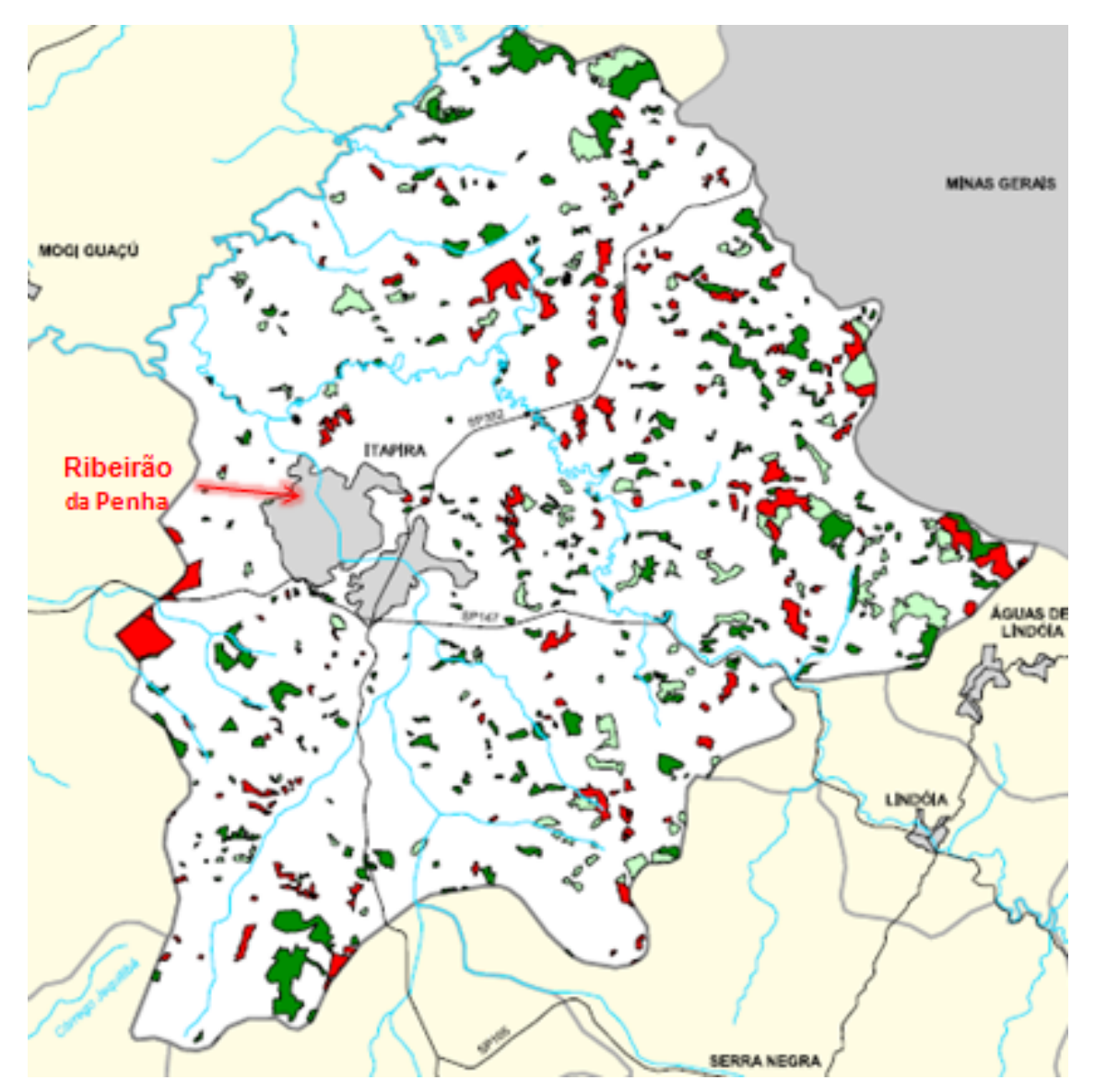

Figura 2. Área total do município de Itapira-SP mostrando o Ribeirão da Penha contando o perímetro urbano (área cinza). Extraído e modificado Instituto Florestal.

foram transportadas até o local, sendo distribuídas próximas às covas que foram abertas, combinando espécies dos diferentes estádios de sucessão (pioneiras, secundárias e clímax), adaptadas às condições locais. Posteriormente, funcionários da SAMA retiraram o solo dos coveamentos de acordo com o volume dos torrões das mudas.

Com a chegada dos integrantes do CISBRA e moradores locais, foi realizado as orientações pertinentes para a realização do plantio, assim como, enfatizado a importância da ação de reconstituição da mata ciliar para os cursos d'agua e os benefícios para as nascentes existentes no local.

\section{RESULTADOS E DISCUSSÃO}

Para o plantio realizado na APP localizada no entorno das nascentes do bairro Braz Cavenaghi, município de Itapira-SP, foram selecionadas um total de 150 unidades arbóreas de espécies nativas da região.

Em observação do local, nota-se um grau de degradação moderado e intenso aos arredores das nascentes, sendo um fator preocupante, o déficit ciliar em sua cabeceira, local por onde a água superficial escorre, mostrando indícios de processo erosivo. Assim, foi preconizado o plantio na cabeceira desse fragmento florestal conforme demonstrado na figura 1, visando atenuar essa erosão.

Estudos revelam que as espécies arbóreas protegem de várias maneiras os solos da erosão. A copa das árvores retarda a velocidade das gotas de chuva, e os restos vegetais que caem sobre a terra protegem o solo do impacto direto da água e as raízes além de servir como uma contenção mecânica, tornam o solo mais poroso e permeável, ajudando a água a infiltrar-se na terra em vez de escorrer sobre ela, em paralelo favorecendo a manutenção dos reservatórios subterrâneos.

Apesar da reconhecida importância ecológica evidente nestes últimos tempos, em que a água vem sendo considerada o recurso natural mais importante para a humanidade, as florestas ciliares continuam sendo eliminadas cedendo lugar para a agricultura e a pecuária e, na maioria dos casos, sendo transformadas apenas em áreas degradadas, sem qualquer tipo de produção.

$\mathrm{Na}$ reconstituição ciliar descrita neste tra- 

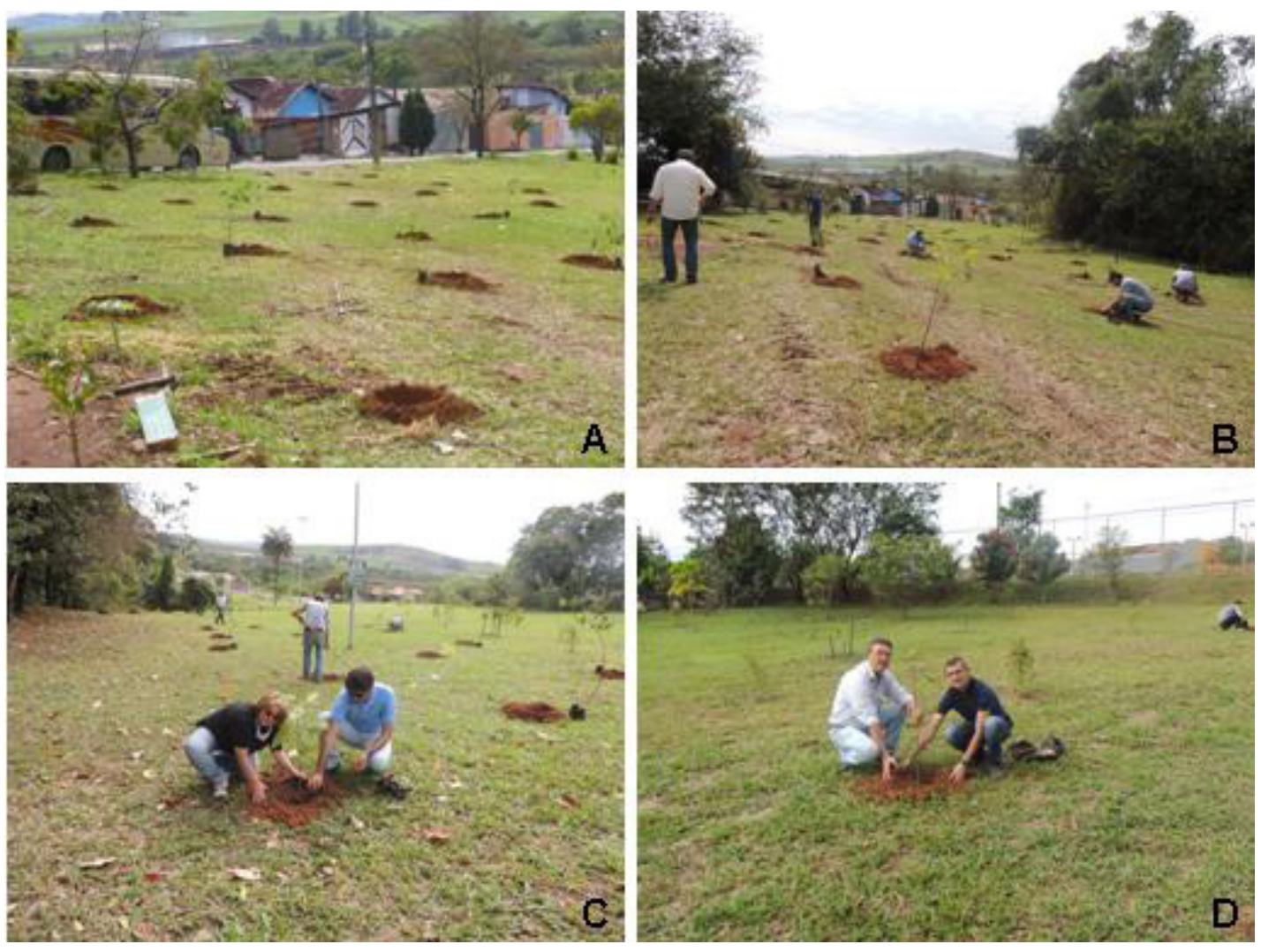

Figura 3. Reconstituição da mata ciliar das nascentes do bairro Braz Cavenaghi, Itapira - SP. Em A, os coveamentos, B, C e D o plantio diretos das mudas na área de cabeceira das nascentes.

balho, a distribuição das mudas na área de plantio foram estabelecidas levando em consideração seu estado sucessional, onde as espécies pioneiras e secundárias iniciais, de rápido crescimento, venham a sombrear e propiciar um ambiente adequado às mudas das espécies que se desenvolvem melhor à sombra - secundárias tardias e climáceas.

A ação da reconstituição ciliar da cabeceira destas nascentes teve inicio com as orientações de plantio das mudas, sendo abordado os benefícios desta ação de educação ambiental pelos técnicos da SAMA. Posteriormente, integrantes do CISBRA e representantes da comunidade do entorno formaram duplas e percorreram os coveamentos realizando o plantio das espécies selecionadas (Figura 3), possibilitando a cada participante plantar um numero significativo de mudas e colocar em prática o conteúdo trabalhado nas reuniões temáticas do consórcio.

Posteriormente ao plantio, técnicos da SAMA revisaram as mudas plantadas e inseriram os tutores em cada planta para direcionamento de crescimento e a proteção de fatores climáticos ventos, chuvas, outros.

Segundo Biella e Costa (2006), a proteção das nascentes trabalha principalmente com a recu- peração das matas ciliares, que são sistemas vegetais essenciais ao equilíbrio ambiental e, portanto, devem representar uma preocupação central para o desenvolvimento dito sustentável. A preservação e a recuperação das matas ciliares, aliadas às práticas de conservação e ao manejo adequado do solo, garantem a proteção deste que é um dos principais recursos naturais: a água.

Após as orientações pertinentes ao plantio, os benefícios da reconstituição da mata ciliar para o meio ambiente, nascentes e para o curso d'agua em questão e levando em consideração do local se tratar de uma área urbana favorecendo desta forma a arborização urbana, foi observado uma percepção de grande motivação e curiosidades por parte dos participantes quanto ao período de desenvolvimento das plantas, de que forma são produzidas, identificação das espécies, características morfológicas, aspectos paisagísticos "fenologia" dentre outros.

Segundo Seniciato e Cavassan (2004), as aulas ou ações desenvolvidas em ambientes naturais têm sido apontadas como uma metodologia eficaz tanto por envolverem e motivarem crianças e jovens nas atividades educativas, quanto por constituírem um instrumento de superação da 
fragmentação do conhecimento.

Por se tratar de uma área localizada dentro do perímetro urbano, foi observado no entorno uma ação antrópica significativa o qual faz o espaço, o território, o lugar, a região e a paisagem se alterarem. Ao iniciar as atividades neste local foi percebido a ação antrópica com o deposito de resíduos sólidos nas margens do fragmento florestal e no seu interior. Isso ocorre devido a não existência de proteção adequada, acesso humano e proximidade de residências das áreas de proteção permanentes.

Quando o resíduo é acumulado próximo às nascentes, favorece ambientes de abrigo e procriação de vários animais, dentre eles transmissores de doenças. Além de ser um potencial contaminador do solo que, por percolação ou escoamento superficial irá afetar a agua ou mesmo os reservatórios subterrâneos.

Em conversa com os moradores do entorno, os mesmos relatam que o Poder Público já realizou a limpeza do local, a Rede Social de Itapira composta por diversos segmentos da sociedade, integrantes do Conselho de Defesa do Meio Ambiente e SAMA já realizaram ações ambientais no sentido de conscientização da população sobre a importância desse fragmento florestal e de suas nascentes com resultado pouco satisfatório.

Apesar de ser indiscutível que os problemas ambientais devam estar entre os assuntos prioritários na sociedade moderna e que as ações de campo são um instrumento eficiente para o estabelecimento de uma nova perspectiva na relação entre o homem e a natureza, o plantio de arvores no campo com os integrantes do Cisbra e a comunidade local favoreceu também o trabalho coletivo, em equipe, visando uma ação harmoniosa e cooperativa em busca de um mesmo objetivo e a aquisição da responsabilidade do cuidar junto à atividade desenvolvida. As atividades de campo permitem também a exploração de conteúdos conceituais, procedimentais e atitudinais, o que possibilita que sejam também de grande valia em programas de EA.

Portanto, a prática da EA, como transmissora de procedimentos ambientalmente corretos, nem sempre garantirá a formação de atitudes ecológicas, sendo que o indivíduo apenas agirá de acordo com o que se espera dele. A formação de uma atitude ecológica está intimamente relacionada com o sistema de valores que orientam as relações do indivíduo com o meio, o que, consequentemente, norteará os posicionamentos na escola, assim como, em outros espaços de sua vida (CARVALHO, 2006).
As atividades de campo permitem o contato direto com o ambiente, possibilitando que os participantes se envolvam e interajam em situações reais. Assim, além de estimular a curiosidade e aguçar os sentidos, possibilita confrontar teoria e prática.

\section{CONSIDERAÇÕES FINAIS}

A simples observância da legislação ambiental brasileira bastaria para se perpetuar estas nascentes, mas por força da ostensiva demanda imobiliária, as referidas áreas encontram-se em locais desmatados, drenados, canalizados, aterrados ou simplesmente utilizados como deposição de entulhos e resíduos urbanos diversos.

A falta de proteção e a proximidade com residências são os principais aspectos que influenciam negativamente nos impactos evidenciados nas nascentes estudadas. Assim, é de extrema relevância novos estudos e trabalhos de educação ambiental com os moradores do entorno desta área mostrando a importância de se preservar e as consequências que estão causando devido ao desrespeito com esse fragmento florestal.

Por muito tempo, a sociedade aceitou a degradação das matas ciliares e, hoje, estamos colhendo os frutos dessas ações. A partir das ações de mobilização da sociedade e do atendimento da Prefeitura Municipal de Itapira através da SAMA, observa-se a formação de uma rede entre o órgão público, comunidades, escolas e outros órgãos, onde permeiam não somente atitudes pontuais relacionadas às questões ambientais, mas também ações e iniciativas futuras desses órgãos no que se refere à educação ambiental para o município.

Por tanto, a informação aliada com uma atitude construtiva geram ações que podem mudar a visão da sociedade em relação ao meio ambiente que os cercam, e gerar cidadãos com um olhar ampliado para mundo. Essa cumplicidade entre todas as esferas presentes no espaço urbano é a condição básica para o alcance de uma melhor qualidade ambiental urbana e um padrão mínimo de qualidade de vida humana. Neste sentido, a educação ambiental é uma ferramenta na realização de ações para melhoria da região, intensificando-se, com isto, a demanda por atividades que estimulem o desenvolvimento de uma consciência ambiental, não só ecológica, do ponto de vista da natureza, mas também visando às questões social, cultural e econômica. 


\section{REFERENCIAS BIBLIOGRÁFICAS}

ANDRADE, J.; SANQUETTA, C. R.; UGAYA, C. Identificação de Áreas Prioritárias para Recuperação da Mata Ciliar na UHE Salto Caxias. Espaço Energia, n. 3, 2005.

BIELLA, C. A. COSTA, R. A. ANÁLISE DA QUALIDADE AMBIENTAL DAS NASCENTES URBANAS DE CALDAS NOVAS - GO. VI Simposio Nacional de Geomorfologia/ Regional Conference on Geomorphology, Goiana, 2006

BOTELHO, S. A.; DAVIDE, A. C. Métodos silviculturais para recuperação de nascentes e recomposição de matas ciliares. In: SIMPÓSIO NACIONAL SOBRE RECUPERAÇÃO DE ÁREAS DEGRADADAS, 5., 2002, Belo

Horizonte. Anais... Belo Horizonte: 2002. p. 123-145.

BOTELHO, S. A. Princípios e métodos silviculturais. Lavras-MG: UFLA. 2003.144p.

BRASIL, Novo Código Florestal, Lei n ${ }^{\circ} 12.651$, de 25 de maio de 2012. Disponível em: < http://saema. com.br/files/Novo\%20Codigo\%20Florestal.pdf > Acesso em: 02 de Janeiro de 2012.

CALHEIRO, R. O. Preservação e recuperação das nascentes (de água e de vida).4.ed. Piracicaba-SP, 2007. p. 40.

CARVALHO, P. E. R. Técnicas de recuperação e manejo de áreas degradadas. In: GALVÃO, A. P. M. Reflorestamento de propriedades rurais para fins produtivos e ambientais: Um guia para ações municipais e regionais. Brasília: Embrapa Florestas, 2000. cap. 14. p. 251-268.

CARVALHO, I. C. M. Educação ambiental: a formação do sujeito ecológico. 2 ed. São Paulo: Cortez, p.255, 2006.

MINISTERIO DO MEIO AMBIENTE - SP. RESOLUÇÃO CONAMA n ${ }^{\circ}$ 303. Disponível em: < http://www.mma.gov.br/port/conama/legislacao/ CONAMA RES CONS 2002 303.pdf> Acesso em: 07 de Setembro de 2013.

DURIGAN, G.; SILVEIRA, E. R. Recomposição de mata ciliar em domínio de cerrado, Assis, SP. Scientia Florestalis, v. 56, p.135-144, 1999.
FERREIRA, M. J.; PEREIRA, I. M.; BOTELHO, S. A.; MELLO, C. R. Avaliação da Regeneração Natural em Nascentes Perturbadas no Município de Lavras, Mg. Ciência Florestal, Santa Maria, v. 19, n. 2, p. 109-129, abr.-jun., 2009.

INSTITUTO DE PESQUISAS TECNOLÓGICAS DO ESTADO DE SÃO PAULO S.A. - IPT. Mapeamento geológico na escala 1:50.000 das folhas Mogi Guaçu e Águas de Lindóia, 1982. Disponível em: <http://www.ipt.br> Acesso em: 05 jan. 2007.

GUERRA, A. T. Novo dicionário Geológico-geomorfológico. 3.ed. Rio de Janeiro: Bertrand Brasil, 2003.

INSTITUTO BRASILEIRO DE GEOGRAFIA E ESTATÍSTICA - IBGE Cidades: Censo 2010 Disponível em: < $\underline{\text { http://www.ibge.gov.br/cidade- }}$ sat/topwindow.htm?1> Acesso em 22 de dezembro, 2011.

INSTITUTO FLORESTAL - SIFESP: Sistema de Informações Florestais do Estado de São Paulo. Disponível em: $<$ http://www.iflorestal.sp.gov.br/sifesp/ estadosaopaulo/itapira.pdf?opcoes=itapirapdf $>$ acesso em 28 Junho/2012.

OKUYAMA, K. K; ROCHA, H. C.; NETO, W. H. P; ALMEIRA, D.; RIBEIRO, D. R. S. Adequação de propriedades rurais ao Código Florestal Brasileiro: Estudo de caso no estado do Paraná. Revista Brasileira de Engenharia Agrícola e Ambiental, v.16, n. 9, p.1015- 1021, 2012.

OLIVA JÚNIOR, E. F.; SOUZA, I. S. Os impactos ambientais decorrentes da ação antrópica na nascente do Rio Piauí - Riachão do Dantas/SE. Revista Eletrônica da Faculdade José Augusto Vieira, Ano V, n. 7, 2012.

PILICIONI, A. F. Trajetória do Movimento Ambientalista. In: Curso de gestão ambiental, pg 19. ed. Manole, 2004.

SENICIATO, T.; CAVASSAN, T. O. Aulas de Campo em Ambientes Naturais e Aprendizagem em Ciências - Um Estudo com Alunos do Ensino Fundamental. Ciência \& Educação, v. 10, n. 1, p. 133-147, 2004.

SETZER, J. Atlas Climático do Estado de São Paulo. Secretaria da Agricultura. São Paulo, 1976. 
SILVEIRA, A. F.; BUENO, L. M. M. Estudos de vulnerabilidade sócioambiental e usos do território na microbacia do Ribeirão da Penha - Itapira-SP Anais do XIII Encontro de Iniciação Científica da PUC-Campinas, 2008. Disponivel em: $<\underline{\text { http: //www. }}$ puc-campinas.edu.br/pesquisa/ic/pic2008/resumos/Resumo/\%7B1D573D1D-BC9B-4381-8690F1079DF4C01E\%7D.pdf $>$ Acesso em: 02 de Janeiro 2012.

TERRES, C. A.; MÜLLER, M. M. L. Proposta de recuperação de área degradada às margens do Arroio do Engenho na Vila Concórdia, Guarapuava - PR.

UNICENTRO - Revista Eletrônica Lato Sensu, n. 5, 2008. Disponível em: < http://web03.unicentro.br/ especializacao/Revista Pos/P\%C3\%A1ginas/5\%20 Edi $\% \mathrm{C} 3 \% \mathrm{~A} 7 \% \mathrm{C} 3 \% \mathrm{~A} 3 \mathrm{o} / \mathrm{Agrarias} / \mathrm{PDF} / 2$-Ed5

CAPropo.pdf $>$ Acesso em: 03 de jan. 2012. 